\title{
Tentative Analysis on Healthy Condition and Improvement of High-school Students
}

\author{
Youfeng Wang ${ }^{1}$ \\ ${ }^{1}$ Oxbridge College, Kunming University of Science and Technology, Kunming, Yunnan, China
}

Keywords: College Students; Physical Quality; Healthy Situation; Improved Measurement.

\begin{abstract}
As we all know, health is the fundamental factor of human beings. Without a strong figure, we students could not show our ability even with plenty knowledge and skill. Therefore, high-school managers should pay higher attention to the healthy situation of students, and explore more effective measurement to strengthen it which will improve students' physical quality. It is a worried issue that nowadays, our college students are really worse with their healthy situation. This article employs the method of investigation and research, and tries to find an effective way to strengthen students' physical quality. Moreover, high school should cultivate the consciousness of health among students, developing various outdoors activities, training them to possess fine eating habits and reasonable time table as well, and it will help them improve healthy situation and physical quality.
\end{abstract}

\section{Introduction}

With the issues like obesity, suicide and depression occurred frequently among high-school students, they are focused on by the whole society. Many people think that to trace these issues, the key point is their healthy problems. Nowadays, students burden too much from their parents that they want kids to bring honors for family and thus lead the students to be fragile. Moreover, together with worldwide usage of internet, students spent much time on it and ignore physical exercise, then it lead to a worse healthy situation in a long term. However, even there is no body alarm appeared in present, when they step into society and work for a while, the students will find the fact that they have bad health and some may possess illness. [1] Therefore, high school should focus on students' healthy matters while educating and cultivating them, exploring the effective measurements to organize and encourage students. Thus, it is essential to know students' healthy situation and organize physical exercise in the college.

\section{The research and study on college students' physical health}

In order to know the high-school students' healthy situation, the writer of this article accord to the information of Implementation Plan of All-China Students' Healthy Situation, taking students from a specific region as subjects to develop the research.

The research and study on college students' physical health. Subject. Students from a specific region were taken as subjects to develop the research about healthy situation.

Method. Methods employed in this research:

The documentation method: Consulted high-school library, China Series full-text database and other academic websites, and the writer derived related materials of high-school students' physical health and then did a concrete study with which to analyze their healthy condition.

The comparative analysis: in order to reassure the healthy condition of subjects, the writer referred to reached materials, comparing body shape, skill and body quality of students.

The questionnaires method: in order to know the healthy condition of students, the writer combined conditions of their daily life and exercise, and thus designed a survey about their healthy condition which asked subjects to answer the questions it gave. Then analyze the result of the survey and understand their healthy conditions. 
Research and study. Based on the methods above, the writer collected related materials to analyze it as the basis of healthy analysis of high-school students. And in the meanwhile, the writer designed survey which conferred daily life, sports exercise and self-condition of students. Among 1000 surveys, there were 954 students took part in. After analyzing with effective survey, the writer could get information about healthy condition of students from it. [2]

The analysis of students' sports exercise

The basic condition of students. According to the survey of students' physical quality, there is basic information about contemporary college students. The main students taken part in are freshman, sophomore, junior, and among them, boys are the most one. Thus in the result of survey shows $50 \%$ students smoke sometimes while 30\% not, and 20\% students smoke usually; there are $1 \%$ students drink alcohol 5 or 7 times in a week while 35\% students never drink it, and 20\% students 3 or 4 times a week. Those who shaped a reasonable and regular eating habit are $40 \%$ which means nearly $60 \%$ students are in opposite. 15\% students sleep for more than 8 hours, and $15 \%$ sleep between 7 to 8 hours, those who sleep between 6 to 7 hours are 15\% while 30\% below 6 hours; there are 10\% students spend more than 5 hours on watching TV and play computer games and $30 \%$ on it between 3.5 to 4.5 hours, those who are in 2.5 to 3.5 hours are $30 \%$ in total while $15 \%$ in 1.5 to 2.5 hours. [3] Therefore, basic on the analysis above, we could make sure that the contemporary college students possess bad daily life habits and they didn't shape a good habit in sports exercise.

\section{The analysis of sports exercise situations}

According to the basic understanding of students, we could find that their life habits are not good and not shape a well sports exercise habits. In order to prove that, the writer analyzed their attendance in sports exercise, they are:

The attendance of sports exercise in normal teaching. Through the communications with college sports teacher, the writer knows that under the quest of Outline of Teaching Guidelines for Physical Education in National Institutions of Higher Learning, most sports course are reasonable are good to students' health. However, less students could take part in sports exercise totally, for the influenced by factors like equipment insufficiency and low interests of students.

The attendance of sports exercise in spare time. In the spare time, most students didn't do the sports for their low interest in it. They couldn't take part in positively and try to the sports items. Besides, school seldom organized outdoors activity in the spare time for students exercising, which limits sports exercise in some degree. Thus there are few opportunities for students to take part in sports in spare time. It is influenced largely by objective and subjective factors. [4]

The analysis of high-school students' healthy condition. Basic on the research and analysis above, we could make sure that the number of high-school students are increasing largely these years and more and more students appeared healthy problem that lead to the rate of physical quality reduce. In the research, we find that the average eye sight of them are low, it is related largely with watching tv and playing mobile phone; the lung capacity of them are lower than standard in this age groups, which we could sure that their cardio-pulmonary function and endurance level are low; compare with standard, their muscle power just reach the passing state, which could prove that these students pay less attention to self exercise; we also find that the lasting time of their endurance run are short, it means their endurance are worse. After a series research and analysis, it is easy to find that contemporary high-school students in a bad healthy condition.

So, what caused the issue?

Lack of exercise time. Although everyone knows that the direct way to be strong is sports exercise, they also know it is easy to be tired and need to persist, many students take part in it are not positively for thinking they are good in healthy condition. And in the college, students are more free to reach the society widely which stimulate their curious and interest to take part in various activities, however, these activities together with daily learning schedule occupied their main time, then there are little time for them to do the exercise. Besides, most students are tend to surf in the internet, play games or watch TVs which cost another amount of time, and finally they quit the sports exercise. The each organ function of their body will be worse if not do the exercise for a long term. [5] 
The level of value for physical quality is not enough. The contemporary high-school students pay little attention to their physical quality, it reflected by ignoring healthy diet and lacking sleep which burdens heavily for their body and then the physical quality becomes worse than before. Besides that, the high school itself also not attaches great importance to protect students' physical quality or take some effective measurements to resist their behavior, like opening healthy literature, organizing activities or making rules to limit their behaviors.

Lack of exercise. Once we being old suffering illness and pains, we then regret not pay attentions to exercise before. And it is what contemporary high-school students showed us, they waste their healthy quality as young. They ignore exercise like walking after meals, regular long-distance jogging or taking part in outdoors activity, and it appears some small symptoms such as anemia, gastroenteritis in the process the students use up their body. Even though these small symptoms won't harm seriously, it appears frequently is to alarm students to pay attention to the healthy condition. Thus, contemporary students should take it seriously and do the exercise positively. [6]

\section{The effective measurement to strengthen high-school students' physical health}

According to the worse healthy condition of students, there should be effective measurement to improve and help students shape good life habits, regular time table, reasonable diet, daily exercise and so on. To adjust physical condition will strengthen physical quality and lead to a healthy body which could shoulder burdens to construct the country. Therefore, how to improve contemporary students' worse healthy condition? There are the suggestions from the writers:

To cultivate the healthy consciousness of students. The reason that contemporary high-school students pay less attention to healthy condition is they lack consciousness of it and are lured by some social phenomenon or members, thus take part in these social activities ignoring sports exercise. Therefore, we should strengthen their consciousness of exercise firstly to arouse their interests with sports, and then shape a fine exercise habits. The concrete methods are:

Firstly, high schools should organize healthy literature, healthy quality discussions or activity regularly. In the process of attendance, students could learn more knowledge about healthy quality and re-know healthy quality to set up healthy consciousness. Then, they will recognize the importance of staying healthy.

Secondly, high schools should set up physical health course and develop related education. Combining cases and examples to explain the bad behavior will do harm for health while teaching, like smoking and drinking alcohol harm the body; it is also need to combine cases and examples to show the disappointment of worse healthy condition, such as symptom analysis caused by worse healthy conditions. To explain the cases in the process of physical quality teaching, could show the importance of health more vivid, and it could touch the students to keep the body healthy. [7]

Rich outdoors activity. As the personnel of every high school, the students should be responsible by their schools that the latter need to organize examination of students' healthy condition and design reasonable exercise plan for students to develop sports exercise, according to the results of it. Besides the personnel exercise plan, school also need to organize regular outdoors activities, such as climbing, tug of war or swimming. Through them, students could take part in the positive activities. School should resist them to join some social activities, and it could not only exercise their body, but also promote the communications between students and teachers which lead them to a more harmony relationship. Thus, to develop outdoors activities will help students exercise their body, increasing physical quality, it also help students get better development of ability, quality, consciousness and spirits

Reasonable nutrition and balance the dieting. According to the results of survey, one of the reasons that caused their worse life habit is irregular dieting which lead to a nutrition insufficiency and then influence their physical health. Thus, it is also important to improve eating habits while students want to promote physical quality. How to help students change the bad eating habits into reasonable one?

First of all is interference of diet, which means to pay attention to the measurement like a scientific breakfast and nourished lunch, and interfere their basic diet. It is essential to develop related diet improving activities, such as "nutrition project for young students" promoted by teachers and students 
to show the importance of healthy diet. Or setting up the way "punch the clock"to supervise each other and let them take part into promoting diet. After practice for a while, there must be part of students shape healthy diet habits and then let them to influence others. Once it expanded, more and more students will benefit from it with healthy diets.

Second method is to develop literature of reasonable diet. In order to help students with reasonable diet and derive balanced nutrition, schools should organize related literature to let students know how to eating reasonable, then they will pay attention to eating with a right diet in daily life and grain nutrition to strengthen the body.[8]

To organize reasonable time table. A fine time table will assure students' physical health and keep them in a well spirits state. Because in present state, most students usually stay late that turns out a low recovery of self organ function, then it harm the body and healthy condition turns down finally. In order to let students have good physical quality, schools also need to help them shape fine time table. The concrete ways are:

First of all, school could organize a series of educational activities to show the importance of reasonable time table and the meaning of "getting up early and sleep early", let the students to recognize a right time table is important to health gradually.

Secondly, schools should strengthen time table in the campus. It asked dormitory teachers to be strict with students, which means check seriously the sleeping situations of each rooms while reach the sleeping time. Teachers also need to punish those who are back late or play games, then help them shape good habits.

Thirdly, schools should manage morning exercise in every morning. It asked students to running around playground after getting up early, which help them shape well time table habits and also exercise their body. [9]

\section{Summary}

A healthy body is the fundamental factor for a long-term hard working, there is no use for a skill and ability to display if without it. Therefore, we should pay great attention to high-school students' physical health, and explore the effective measurement to organize them to do sports exercise. However, it worried us that contemporary students' healthy condition is worse. Therefore, high school should help them to shape consciousness of health, developing plentiful outdoors activities or cultivating them with good eating habit, balanced diet and reasonable time table. With these measurements, student will have a better life and do well in body exercise, then improve present healthy condition gradually and strengthen their body to have a healthy one.

\section{References}

[1]Guo Wen, Cao Lei, Chen Zhipeng. Effects of different sports interventions on physical fitness, college students' physical fitness, sports pleasure and regular exercise [J]. Journal of Wuhan Institute of Physical Education,2012,46(3):91-96.

[2]Fan Guangjun. Physical health status and promotion strategy of college students in China--Comparison of physical fitness differences between Chinese and foreign college students [J].Academic Journal of Zhongzhou,2014(3):75-77.

[3]Liu Xin, Luo Xu, Zhang Li. Study on self assessment of College Students' physical fitness and its influencing factors--Taking college students in Tianjin as an example [J]. Journal of Chengdu Sport University,2010,36(1):76-79.

[4]Liu Jianping, Li Chaohonng, Yu Yu. Innovative research on the effects of ecological sports on College Students' physical fitness and physical fitness behavior - Taking Xiang Nan College as example[J].Sports,2014,(24):41-42. 
[5]Lu Xiangqun. Study on monitoring mechanism of physical fitness of college students in Shanghai --Based on the implementation of national standards for physical health of students [D].Donghua University,2013.

[6]Xiao Tao, Zhen Jie. Study on the present situation and improvement strategy of College Students' physical fitness -Taking $\mathrm{He}$ Nan province as example [J]. Contemporary Sports Technology,2014(14):95-96.

[7]Zhang Nannan. Analysis on the Common Problems of Physical Fitness Test among College Students [J]. Science Sporting Goods,2016(8):165-166.

[8]Wang Ping. Study on the status quo and intervention measures of physical health of college students in Jiangmen from the perspective of Sociology [J]. Sports science and technology literature Bulletin,2015(10):26-29,46

[9]Jiang Ming,He Zhijin. Physical fitness of college students and reform of Physical Education--A follow-up study on Standard Test of physical fitness among college students in Chongqing [J].Master,2010(12):218-219. 